This item was submitted to Loughborough's Research Repository by the author.

Items in Figshare are protected by copyright, with all rights reserved, unless otherwise indicated.

\title{
A new approach for the patch repair of car parks using galvanic anodes
}

PLEASE CITE THE PUBLISHED VERSION

PUBLISHER

(C) CRC Press

VERSION

AM (Accepted Manuscript)

LICENCE

CC BY-NC-ND 4.0

\section{REPOSITORY RECORD}

Christodoulou, Christian, John Webb, Gareth K. Glass, Simon A. Austin, and Chris I. Goodier. 2019. "A New Approach for the Patch Repair of Car Parks Using Galvanic Anodes". figshare. https://hdl.handle.net/2134/8825. 
This item was submitted to Loughborough's Institutional Repository (https://dspace.lboro.ac.uk/) by the author and is made available under the following Creative Commons Licence conditions.

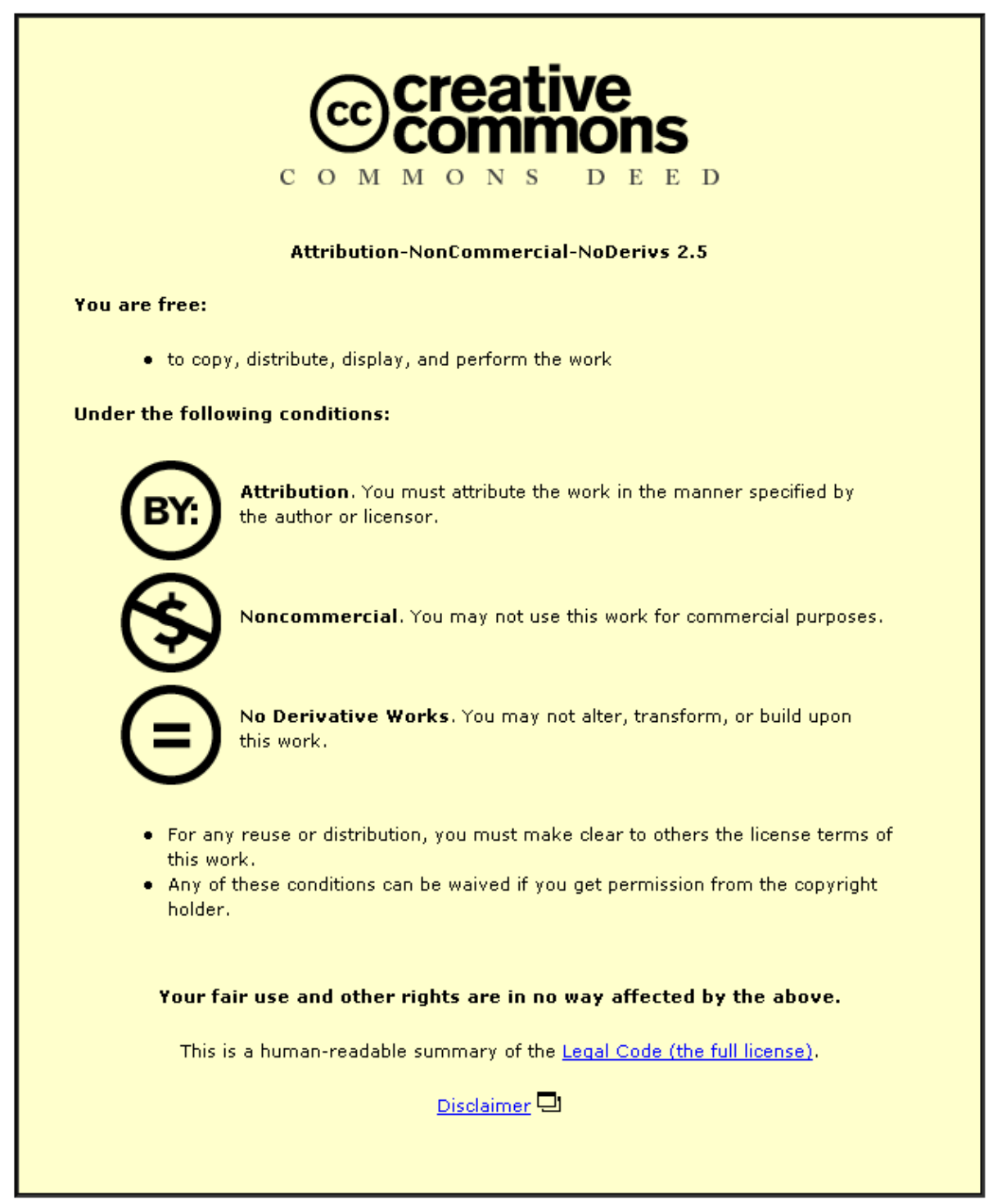

For the full text of this licence, please go to: http://creativecommons.org/licenses/by-nc-nd/2.5/ 


\title{
A new approach for the patch repair of car parks using galvanic anodes
}

\author{
C. Christodoulou \& J. Webb \\ AECOM Europe, 94-96 Newhall Street, Birmingham, B3 1PB, UK, christian.christodoulou@aecom.com
}

G. Glass

Concrete Preservation Technologies, University of Nottingham Innovation Lab, Nottingham, UK, NG7 $2 T U$

S. Austin \& C. Goodier

Loughborough University, Department of Civil and Building Engineering, Loughborough, UK

\begin{abstract}
Car parks constructed with in-situ concrete are generally characterised by very shallow (typically wafer type) slabs which enables fast construction and keeps the self-weight of the structure to a minimum. However, many of these car parks are now displaying signs of significant structural deterioration, mainly due to corrosion damage of the reinforcement leading to spalling of the concrete cover. This paper reviews the corrosion management strategy that was utilised for the concrete repairs of a corrosion damaged car park in the UK. The new approach on this particular scheme has been the positioning of the galvanic anodes. Traditionally they are positioned within the concrete patch repair however, the reinforcement that will be most at risk will be immediately outside this patch repair, and hence in this structure the anodes were placed immediately outside of the patch repair. This paper reviews the performance of these galvanic anodes based on this new approach. The findings help to improve our understanding of the corrosion protection mechanisms and provide a method of assessing performance.
\end{abstract}

\section{INTRODUCTION}

Multi storey car parking structures are a common part of our infrastructure, many of which were built in the construction boom of 1970s using reinforced concrete. The typical structural arrangement was one-way spanning ribbed or two-way spanning waffle floor slabs. These particular structural arrangements offer shallow slab depths throughout the structure as opposed to a traditional one or two way spanning slab with deep beams. The load is distributed between the numerous narrower and shallower ribs and is cost effective for larger spans.

Deterioration of concrete structures can be simplified to the deterioration of the concrete itself and deterioration due to corrosion of the reinforcement (which consequently also has an impact upon the concrete). Under normal circumstances concrete offers a highly alkaline environment with a $\mathrm{pH}$ in excess of 13. Under these conditions, the steel reinforcement develops a protective and passive oxide layer (Page \& Tradeaway 1982).

However, the presence of chlorides (due to the spreading of de-icing salts during winter maintenance) and carbon dioxide $\left(\mathrm{CO}_{2}\right)$ in the atmosphere are some of the major factors responsible for corrosion damage. The former will affect mainly road surfaces and vertical surfaces close to the road, whereas the latter tends to affect all the atmospherically exposed elements. However, carbonation is a much slower process and usually affects areas where there is low cover to the reinforcement. Chloride induced corrosion, once initiated, can propagate and quickly reach very high intensities.

Patch repairs are commonly used to restore the concrete profile. For concrete deterioration relating to carbonation, patch repairs can be very effective as the freshly alkaline mortar will restore the passivity to the reinforcement. However, when the corrosion damage is chloride induced significant quantities of contaminated but sound concrete need to be removed. Bridge Advice 35 (BA 1990) suggests that areas which show chloride concentrations greater than $0.3 \%$ by weight of cement and half-cell potential measurements are higher than $-350 \mathrm{mV}$ should be removed. This approach often makes patch repairs uneconomic for chloride contaminated structures (Christodoulou 2008).

Galvanic anodes have been employed in association with patch repairs to repair reinforced concrete structures. Galvanic anodes are based on the principle that different metals produce different potentials (Broomfield 2000). Therefore, particular metals can be used which will corrode sacrificially to protect the steel reinforcement and offer a protective effect. Compared with a traditional Impressed Current Cathodic Protection system their main advantage is their lack of need for a power supply. In addition, there is no associated complex wiring installation and performance monitoring is less complicated. Howev- 
er, it is acknowledged that galvanic anodes have a lower protective current output and as a result might be ineffective in concrete with corrosion rates (Christodoulou et al. 2009).

Galvanic anodes are traditionally installed within the patch repair. However, these anodes can suffer from poor current distribution. This can be due to the resistivity of the concrete, the arrangement and density of the reinforcement, the concentration of chlorides etc. In general, when patch repairs are to be combined with galvanic anodes, the resistivity of the repair material should be limited to ensure that the protective current from the anodes is delivered to the reinforcement outside the patch repair, which is recognised as an area of high risk (Page \& Sergi 2000).

Half-cell potential mapping is routinely used to assess the corrosion risk. However, the same technique is also utilised to assess the presence of anodes within the patch repair. The work by Elsener (2001) suggests that although it is not currently a requirement by a code of practice to monitor the galvanic anodes, it can be a very effective approach to provide to the client the re-assurance that the rehabilitation design is successful. Also this data can be utilised to revise the original design if necessary.

The objective of this work was to develop a new design approach for concrete patch repairs in association with the use of galvanic anodes. This design approach was used on the concrete repairs of a multi storey concrete car park (MSCP) in the UK where the galvanic anodes were installed within the parent concrete rather than in the patch repair. The anodes were then monitored to assess their performance, thus improving our understanding of the corrosion protection mechanisms.

\section{INITIAL SURVEY}

The MSCP was built in the early 1970s and it has a concrete one-way spanning ribbed type deck arrangement. The structure is receiving high amounts of daily vehicular traffic as it is serving a major shopping centre. The structure received waterproofing to its ground and top floors in the approximate late $1990 \mathrm{~s}$ in order to minimise the ingress of chlorides to the originally unprotected deck.

During the preliminary inspection of the structure it was identified that it suffered significant structural damage to the corrosion of the reinforcement (Fig.

1). This was evident on the decks where the reinforcement was exposed but also on the soffits where there was significant spalling of concrete. In addition, it was apparent that the structure suffered from a significant degree of dynamic cracking and water dripping from one level to the other was observed in a large proportion of the structure. The original construction joints were of poor construction quality and water dripping was again evident. Finally, the majority of the expansion joints had failed allowing water to pass through them and damage the soffits of individual levels.

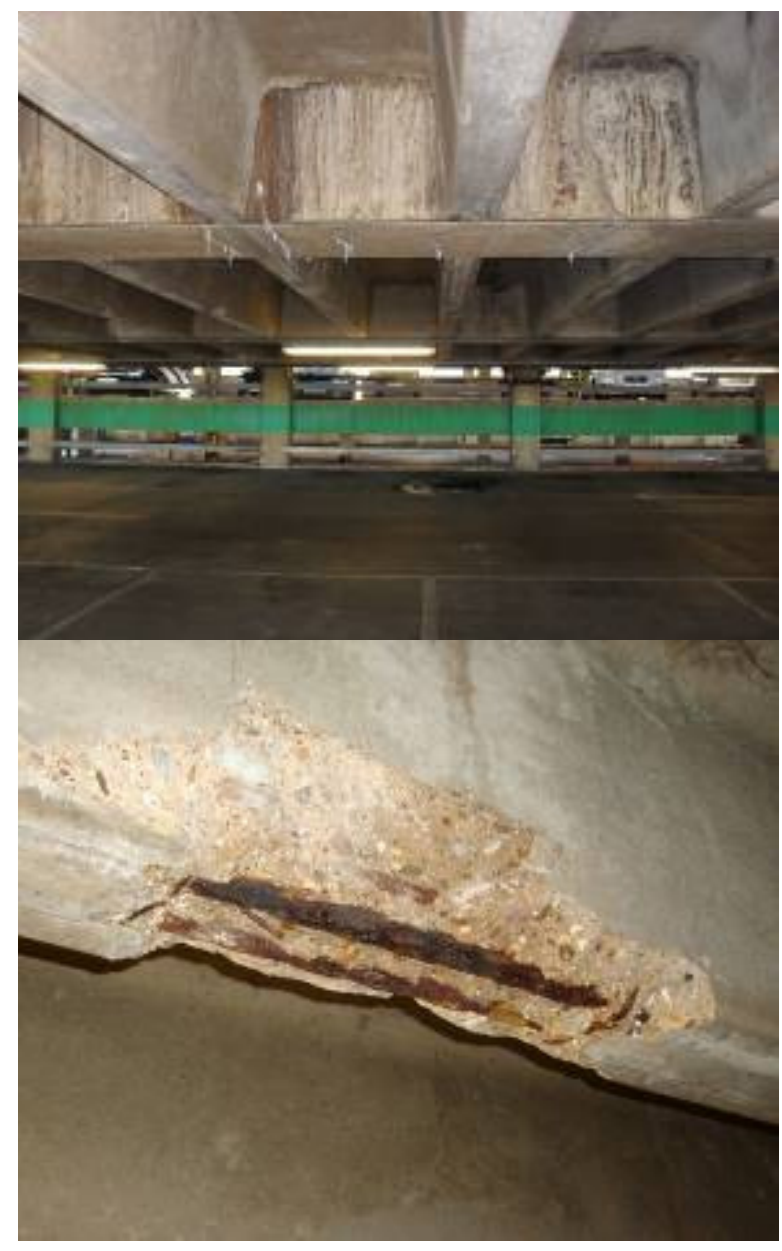

Figure 1: General condition of the soffit

Following the preliminary investigation to identify and record the defects and the analysis of historical data made available by the client, additional testing was undertaken to verify the cause of corrosion of the reinforcement. Intrusive investigations were undertaken in 1997, 1999 and 2008 to determine the depths of carbonation and chloride levels while at the same time assessing the probability of corrosion activity with potential mapping.

Carbonation was identified to be an issue for the parapets as they exhibited a very low cover to the reinforcement. However, the decks appeared to have high levels of chloride concentration at the depth of reinforcement and based on BA 35 (BA 1990) there was a significantly high risk of corrosion. By 2008 , there were locations where the chloride levels were up to $2.92 \%$ by weight of cement even at a depth of 30 to 55 millimetres. Furthermore, the overall depth of the slab spanning between the ribs was at best found to be around $80 \mathrm{~mm}$. Coupled with the low cover to the deck's reinforcing mesh, there were several delaminated areas. 
From the profile of the chloride levels their concentration reduced with depth and they were also reduced as higher levels of the structure were tested. This suggests that chlorides were brought to the unprotected surface of the decks by cars and penetrated the concrete surface, rather than being cast within the concrete. However, on the roof decks, de-icing salt was spread routinely to prevent ponding water from freezing. The ribs of the car park were in general in good condition. However, corrosion damage was observed in areas where the dynamic cracks on the deck were leaking.

\section{DESIGN}

The client's brief called for essential repairs to the car park in order to restore the structural integrity and limit the need for major concrete repairs within the next 10 year period. The client did not favour electrochemical treatment with a complex monitoring system as they did not have the technical expertise to monitor and maintain the system. In addition, they had negative previous experience with Impressed Current Cathodic Protection which was in line with similar experiences published by the Virginia Department of Transportation (Brown \& Sharp 2008).

For this particular project the most suitable corrosion management strategy was that of concrete patch repairs in conjunction with the use of galvanic anodes. Other rehabilitation methods such as impressed current cathodic protection, chloride extraction and re-alkalisation were also considered but not pursued due to their associated technical implications, cost issues and traffic management on a fully live car park.

Galvanic anodes are traditionally installed within the patch repair (British Standards 2000, Broomfield 2000, Sergi 2009). In addition, it is a requirement that the repair material should have a resistivity limited in the range of $50 \%$ to $200 \%$ that of the parent concrete (British Standards 2000). This approach enforces a limitation to the quality of the repair material in order to ensure that the protective current will be able to flow to steel reinforcement.

With concrete patch repairs it is recognised that the reinforcement adjacent to the patch will be at the greatest risk due to the "incipient anode" effect (Raupach 2006, Broomfield 2000, Page \& Sergi 2000). However, it is acknowledged that the protective effect afforded by the galvanic anode will be dependent on resistivity of the concrete, moisture levels and steel density. The design of the repairs aimed to bypass the above issues by installing the galvanic anodes in parent concrete adjacent to the patch repair. Figure 2 illustrates the design approach and the anode installation.

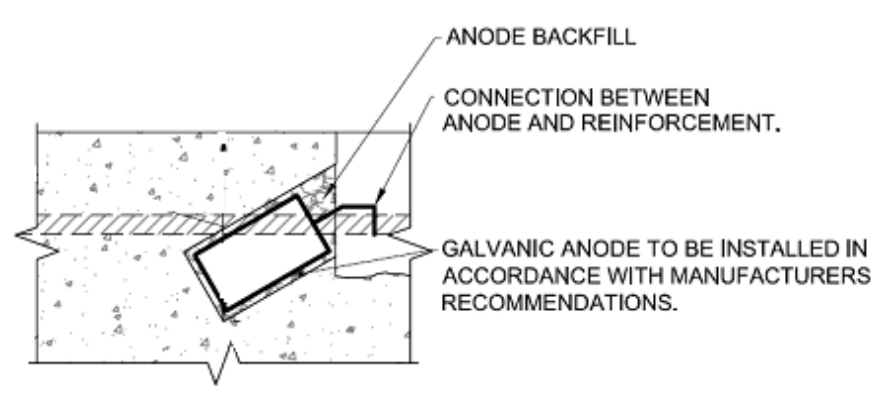

Figure 2: Galvanic anode design

\section{INSTALLATION AND RESULTS}

Following identification of defects, breaking out of the concrete and cleaning of the reinforcement, galvanic anodes containing approximately 65 grams of zinc were installed in drilled holes in the parent concrete at the periphery of the patch (Fig3 3). The original design required the anodes to be placed at a

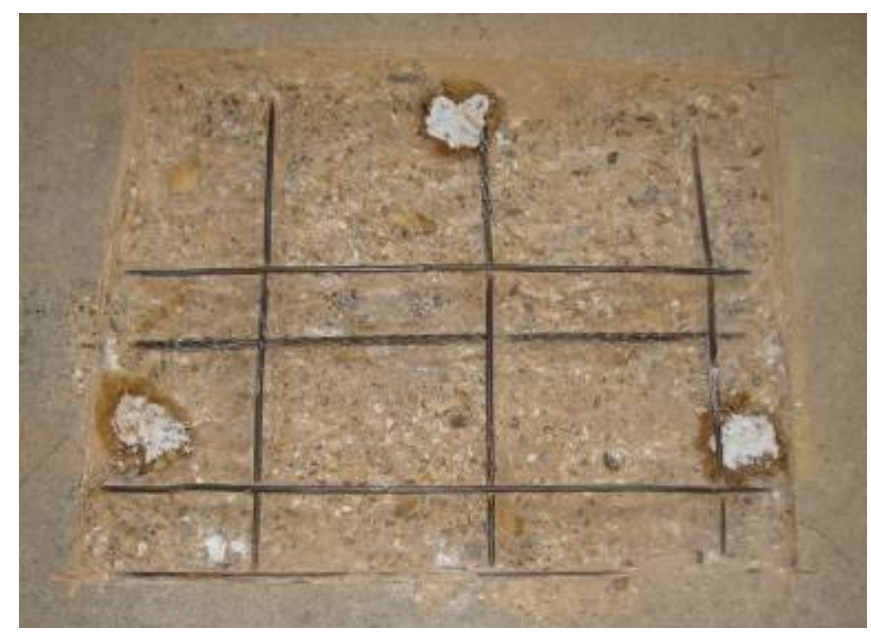

spacing of not greater than $350 \mathrm{~mm}$.

Figure 3: Typical patch repair showing three installed galvanic anodes, before the application of the patch repair material

The anodes were monitored during the repair contract in order to assess their performance. The monitoring was undertaken by means of half-cell potential measurements. It aimed to assess that the installed anodes were active and also quantify the range of the protective effect afforded from the anodes in this particular structure. During the initial testing of the anodes no steel connections to the reinforcement were available. A connection was made to the adjacent steel fencing and therefore all measurements will be relative to the steel fencing and are not absolute values. The data show changes in potential as a function of distance that result from the electric field produced by installed anodes and steel cathode in the concrete at the time of the measurement. 


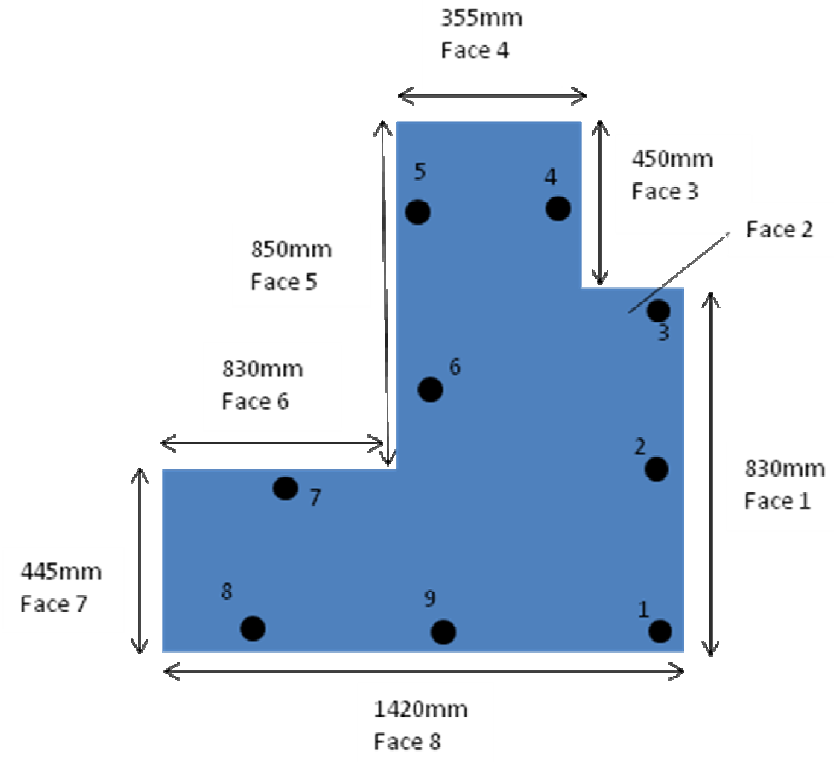

Figure 4: Positions of anodes in patch repair no. 10 (all dimensions in $\mathrm{mm}$ )

Figure 4 illustrates patch repair no. 10 which was undertaken as a trial during November 2010. In total 9 anodes were installed in a $1.1 \mathrm{~m}^{2}$ area of repair. The first test undertaken aimed to identify that all the anodes were indeed active by undertaking potential mapping around the periphery of the patch.

Measurements were obtained at approximately $50 \mathrm{~mm}$ intervals around the periphery of the patch. The tight spacing of potential mapping enabled the location of the presence of anodes with a very high accuracy.
Figure 5 illustrates the results of the potential measurements. As discussed previously the potential values are relative to the steel fencing connection and not those of the reinforcement. From the results it can be observed that all 9 anodes installed were active and offered a protective effect.

The anodes on the patch repair were checked whether they were active at approximately 15 days after placement of the concrete (24/11/2010) and again after 2 months in-service to determine their performance over time. However, the second time not all the faces of the patch repair could be surveyed due to the presence of vehicles.

Following the successful identification of the installed anodes, a second test was undertaken which aimed to assess the polarisation effect afforded by the anodes. The reference electrode was moved away from faces 1 and 4 of the patch repair at intervals of $50 \mathrm{~mm}$. Figure 6 illustrates the results of the potential mapping. It can be observed that on both cases the anodes polarised the reinforcement up to approximately $700 \mathrm{~mm}$ away from the edge of the patch. The test was repeated on several other patches protected with sacrificial anodes two months after installation. The anodes influenced the potential in the parent concrete to a distance of between 400 and $800 \mathrm{~mm}$ from the edge of the patch. The distance of $400 \mathrm{~mm}$ was measured in the case of a patch that contained only one anode and was measured away from the patch on the far side to that containing the anode.

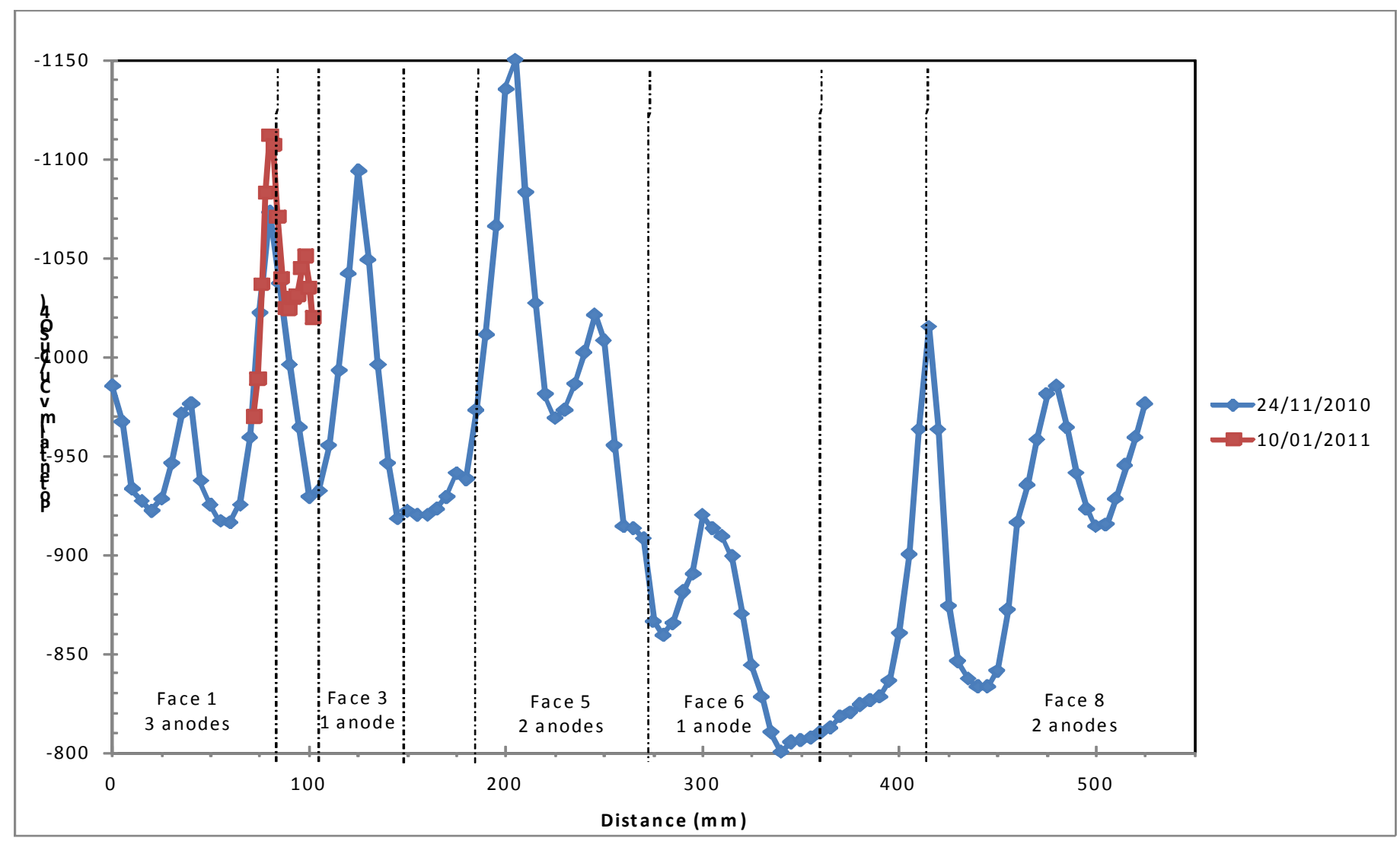

Figure 5: Potentials around patch repair no. 10 


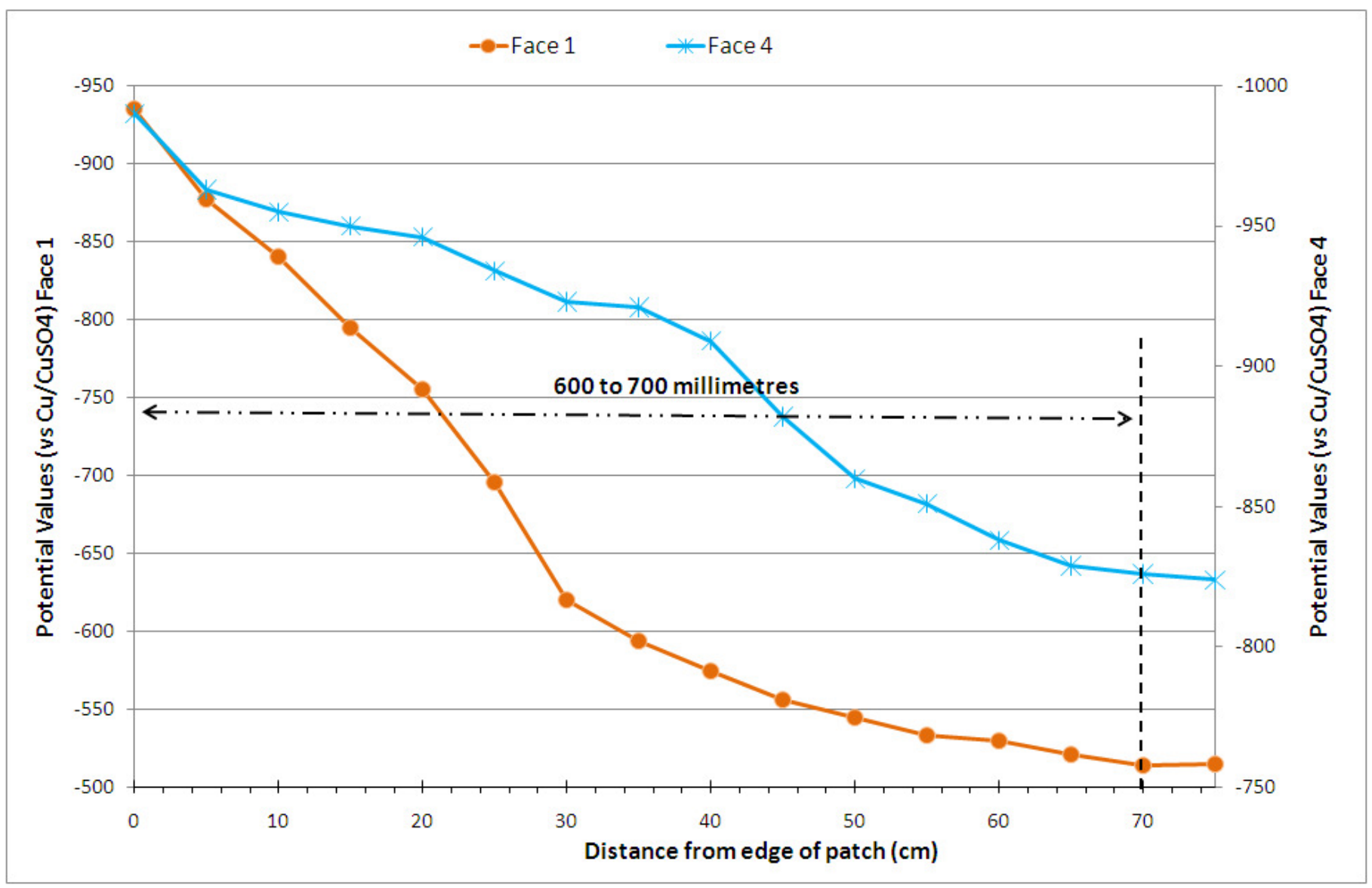

Figure 6: Relative polarisation effect from anodes installed on patch no. 10 after 15 days (Face 1) and after 2 months (Face 4)

\section{DISCUSSION}

A correctly-installed high quality repair material will ensure that the repair will not suffer from any substantial cracking, the concrete matrix will not be as porous and the resultant resistivity will be high. All the above will assist to ensure the longevity of the repair and in this particular case achieving a repair with higher resistivity than the parent concrete will have a favourable effect. The repair due to its higher resistivity will be shielded from chloride ingress and protective current from the galvanic anodes will flow preferentially to the lower resistivity parent concrete where the reinforcement is at a higher risk of corrosion.

Following installation and testing of the galvanic anodes it was identified that they were very effective for the particular structure and the given environmental conditions. In particular the polarisation distance was considerable, indicating that the anodes offered a protective effect at a significant distance from the repair.

The findings formed the basis for an increase in the anode spacing in this structure from a maximum of $350 \mathrm{~mm}$ to $600 \mathrm{~mm}$. This increase in anode spacing offered significant cost savings to the overall costs of the project. Furthermore, in locations where multiple small patches were to be undertaken, the galvanic anodes were placed strategically in order to achieve the desired protective effect whilst at the same time keeping the number of the anodes installed at a minimum.

The findings of the study suggest that potential mapping is an effective technique for the assessment of the performance of galvanic anodes. It does not require the use of highly sophisticated equipment and it can be undertaken by non-specialised Engineers. The potential mapping can assess whether the anodes are active or not and also identify their polarisation effect to the adjacent reinforcement. This suggestion is also in line with the work undertaken by Elsener (2001) who also used potential mapping to assess the effectiveness of concrete repairs in reinforced concrete structures.

Traditionally, half-cell potential mapping in the UK is undertaken based on a $500 \mathrm{~mm}$ grid. ASTM C876 (2009) suggests that for decks with a large surface area a grid up to $1.2 \mathrm{~m}$ may be employed for rapid corrosion assessment of the structure although it is recognised that localised corrosion spots might not be identified. In these localised areas of corrosion the potential measurements might change by several hundred millivolts in less than $300 \mathrm{~mm}$. Undertaking potential mapping at a small grid $(50 \mathrm{~mm})$ has the advantage that any potential localised corroding spots will be identified. In addition, the polarisation effect of the anodes can be better determined.

It is suggested that a new criterion is adopted when assessing the performance of the galvanic 
anodes through the use of half-cell potential mapping. The patch repairs receiving the galvanic anodes should be mapped around their perimeter to assess whether the galvanic anodes installed are active and provide a protective effect. In addition, the polarisation effect offered by the anodes should be checked in order to assess the adequacy of the original design. Anode spacing can then be revised depending on the measured polarisation effect and the required design life of the repairs.

\section{CONCLUSIONS}

The results of this work suggest that the following can be established:

Galvanic anodes outside the patch repair can be successfully installed in order to protect the steel reinforcement in the parent concrete without compromising the quality of the patch repair.

The protective current is delivered to the steel outside the patch which is at greatest future corrosion risk as opposed to clean steel within the patch repair. Materials used for the concrete repairs do not affect the flow of the protective current from the galvanic anodes to the steel in the parent concrete. High quality repair materials and bond coats can be used to prevent future deterioration and prevent chloride ingress down the interface between the repair and parent concrete.

Close interval potential mapping (50mm spacing) is an effective technique to assess the performance of galvanic anodes. Close spacing of the measurements has the advantage that localised corrosion spots can be detected if present.

A new criterion for the assessment of the performance of galvanic anodes is proposed. The anodes should illustrate a measurable influence on the steel potentials away from the area of patch repair that is preferably at least $400 \mathrm{~mm}$ from the edge of the patched area.

\section{ACKNOWLEDGEMENTS}

The authors would like to thank the CICE of Loughborough University and the EPSRC for supporting the lead author throughout the duration of this project.

\section{REFERENCES}

ASTM 2009, Standard Test Method for Corrosion Potentials of Uncoated Reinforcing Steel in Concrete, American Society for Testing and Materials, West Conshohocken, Pennsylvania, USA.

BA 35/1990, Inspection and Repair of Concrete Highway Structures, Departmental Standard, UK.
British Standards Institution (2000), BS EN:12696, Cathodic Protection of Steel in Concrete, London.

Broomfield, J.P. 2000. The principles and practice of galvanic cathodic protection for reinforced concrete structures. Monograph No: 6. Corrosion Prevention Association, Bordon, UK.

Brown, M. C. \& Sharp, S. R. 2008. "Survey of Cathodic Protection Systems on Virginia Bridges" Report VTRC 07R35, Virginia Transportation Research Council (www.virginiadot.org/vtrc/main/online_reports/pdf/07r35.pdf).

Christodoulou, C.(2008. Electrochemical treatment methods of corroded reinforcement in concrete, $2^{\text {nd }}$ International Conference on Concrete Repair, Rehabilitation and Retrofitting, Cape Town, South Africa.

Christodoulou, C., Glass, G. \& Webb, J. 2009. Corrosion management of concrete structures, The Structural Engineer, Volume 87, 23/24, December 2009.

Elsener, B. 2001. Half-cell potential mapping to assess repair work on RC structures, Construction and Building Materials, $15,133-139$.

Page, C. L. \& Sergi, G. 2000. Developments in cathodic protection applied to reinforced concrete, Journal of Materials in Civil Engineering, (1), 8-15, month??? 2000.

Page, C.L. \& Tradeaway, K.W.J. 1982. Aspects of the electrochemistry of steel in concrete. Nature, 297, No. 5862, 109115.

Sergi, G. 2009. Ten year results of galvanic sacrificial anodes in steel reinforced concrete, EUROCORR, Nice, France.

Raupach, M. 2006. Patch repairs on reinforced concrete structures - Model investigations on the required size and practical consequences, Cement and Concrete Composites, 28, $679-684$. 